\title{
Fairness Is a More Effective Interpersonal Motive than Care for Sustaining Prosocial Behaviour
}

\author{
Maurizio Brasini1 ${ }^{12}$, Sasha Del Vecchio ${ }^{3}$, Edoardo Gregni ${ }^{4}$, Chiara Casali ${ }^{1}$, Francesca Mira ${ }^{1}$, \\ Nicolina Capuano4, Valentina Questa ${ }^{1,5}$, Mauro Giacomantonio ${ }^{1,6}$, Francesco Mancini ${ }^{1,2}$ \\ ${ }^{1}$ Scuola di Psicoterapia Cognitiva (SPC), Rome, Italy \\ ${ }^{2}$ Guglielmo Marconi University, Rome, Italy \\ ${ }^{3}$ Università degli Studi de L'Aquila, L'Aquila, Italy \\ ${ }^{4}$ Associazione di Psicologia Cognitiva (APC), Rome, Italy \\ ${ }^{5}$ Roma Tre University, Rome, Italy \\ ${ }^{6}$ Sapienza University, Rome, Italy \\ Email: *maurizio.brasini@psiconet.it
}

How to cite this paper: Brasini, M., Vecchio, S. D., Gregni, E., Casali, C., Mira, F., Capuano, N., Questa, V., Giacomantonio, M. and Mancini, F. (2018). Fairness Is a More Effective Interpersonal Motive than Care for Sustaining Prosocial Behaviour. Psychology, 9, 1426-1443.

https://doi.org/10.4236/psych.2018.96087

Received: April 29, 2018

Accepted: June 26, 2018

Published: June 29, 2018

Copyright $\odot 2018$ by authors and Scientific Research Publishing Inc. This work is licensed under the Creative Commons Attribution International License (CC BY 4.0).

http://creativecommons.org/licenses/by/4.0/

\begin{abstract}
The present study stems from three general assumptions about prosocial behaviour: 1) that it has an evolutionary foundation; 2) that it is sensitive to the interpersonal context in which it takes place; and 3) that it can be supported by different values and motives. An experiment based on the Dictator Game (DG) was carried out, in which two groups of participants with different Social Values Orientation (SVO) established how to share either $€ 30$ gain and a $€ 30$ loss, also considering the varying intentions of the other, which could have been selfish, fair or altruistic. Results confirmed that other's selfish intentions gave rise to a lesser sharing, while other's fair/altruistic intentions were reciprocated with a balanced sharing. However, when sharing a loss, Proself participants tended to exploit the altruistic intentions of the other. Moreover, the analysis of the relevant motivations in the decisions showed that only an individual orientation towards fairness predicted a higher resource allocation; more specifically, sharing a loss when the other showed altruistic intentions was found to be a matter of fairness. These results support the evolutionary hypothesis that fairness, as a key feature of peer cooperation, offers an interpersonal motivational framework more conducive to prosocial behaviour than empathy-based altruism, which is a key feature of the caregiving/care-seeking interpersonal motivational framework.
\end{abstract}

\section{Keywords}

Evolutionary Theory of Motivation, Peer Cooperation, Moral Foundations 
Theory (MFT), Social Values Orientation (SVO), Prosocial Behaviour, Dictator Game (DG)

\section{Introduction}

Which motives underlie human prosocial behaviour? How much of the variability in our willingness to act in favour of other people is explained by individual differences in social and moral values? And what is the role of the interpersonal context in which such decisions take place? By definition, "prosocial" is any behaviour that is intended to benefit others, such as comforting, helping, rescuing, sharing, informing, and teaching (Jensen, 2016). In this paper, an evolutionary outlook on human motivation (Bernard et al., 2005; Cortina \& Liotti, 2005, 2010; Liotti, Fassone, \& Monticelli, 2017) will be adopted as a framework, whilst prosocial behaviour will be put into test by a classical social dilemma: the "Dictator Game" (DG) (Kahneman, Knetsch, \& Thaler, 1986). Firstly, we will consider the converging literature from different fields of study supporting three main assumptions about prosocial behaviour: 1) that it has an evolutionary foundation (par. 1.1);2) that it is sensitive to the interpersonal context (par. 1.2); and, 3) that it may depend upon different interpersonal motives and values (par. 1.3). Moving from these assumptions, in our experiment we will test the hypothesis that individual differences in social values orientation (SVO) tend to emerge according to the perceived intentions of the other by eliciting different "social mentalities"; according to Liotti \& Gilbert (2011), a social mentality is a loose description of how specific biosocial goal-directed motivations (to form certain types of social relationship) orient attention appropriately, recruit relevant cognitive processing and guide emotions and behavioural outputs. More specifically, we hypothesize that a cooperative social mentality, based upon fairness and reciprocity, offers a more stable interpersonal context for prosocial behaviour to emerge with respect to an altruistic and empathic social mentality, which defines a caregiving/care-seeking interpersonal context.

\subsection{Caregiving and Peer-Cooperation in the Evolutionary Theory of Motivations.}

Since Von Neumann's (Von Neumann \& Morgnenstern, 1944) and Kelley's (Thibault \& Kelley, 1959) seminal work, more than half a century of research has led our understanding of how we deal with the conflict between self-interest and other-interest far beyond the idea of the Homo Oeconomicus (Mill, 1836). Nowadays, the evolutionary outlook originally put forward by Charles Darwin seems to better enlighten the comprehension of other-regarding motives in humans: "any animal whatever, endowed with well-marked social instincts, the parental and filial affections being here included, would inevitably acquire a moral sense or conscience, as soon as its intellectual powers had become as well developed, or nearly as well developed, as in man" (Darwin, 1874: pp. 71-72). Dwel- 
ling on this same evolutionary theoretical ground, John Bowlby $(1969,1982)$ was among the firsts to hypothesize the existence of a caregiving system, complementary to that of attachment: "The study of caregiving as a behavioural system (...) is an enterprise calling for attention. Elsewhere (Bowlby, 1982) I suggest it will be fruitful to study its development within a conceptual framework similar to that adopted here for the development of attachment behaviour, namely as the product of interaction between a strong genetic bias to develop certain types of behaviour and the particular sequence of environments, from infancy onwards, within which development takes place." (ibidem, p. 299). More recently, a few authors have converged on the idea that cognitive processes and behaviours are oriented by a finite number of psychobiological systems, whose goals are innate and set by the evolution of the species, whereas their functioning is shaped by interpersonal experience; these systems are named either «motivational systems» (Gilbert, 1989; Lichtenberg, 1989; Liotti, 1989, 2001), or «emotional operating systems» (Panksepp, 1998), or "action systems" (Van der Hart, Nijenhuis, \& Steele, 2006; Ogden, Minton, \& Pain, 2006). Bowlby's hypothesis about the existence of a caregiving motivational system has received strong empirical support (Solomon \& George, 1996; George \& Solomon, 2008); accordingly, the sensitivity to other people's needs, together with a caring state made of a sense of compassion and distress for other people's suffering, are deemed to provide the foundation for an adaptive function of non-exclusive altruism (Mikulincer et al., 2005; Swain et al., 2012). Nevertheless, prosocial tendencies can be explained by yet another interpersonal motive: that of peer cooperation. The ability to share intentions and to work jointly with others towards a shared goal are seen in great apes, and also in infants from the age of nine months onwards (Tomasello, 1999, 2009), together with a sense of fairness and equity (Schmidt \& Sommerville, 2011; Sommerville et al., 2012), representing a decisive step towards the emergence of an "objective" morality in humans (De Waal et al., 2006, 2014; Tomasello, 2016). In this view, peer cooperation is seen as a higher-order motivation for prosocial behaviour than caregiving; indeed, cooperative motives allow the formation of broad coalitions, an ability which co-evolved with the size of neocortex and the complexity of social interactions in all species (Dunbar, 1998; Bernard et al., 2005; Pérez-Barbería, Shultz, \& Dunbar, 2007; Street et al., 2017; Fox, Muthukrishna, \& Shultz, 2017).

\subsection{The Interplay between Individual Differences and the Interpersonal Context}

Although the evolutionary theory of motivations offers a suitable framework for understanding the emergence of prosocial behaviour which is compatible with the social psychology domain (Fehr \& Fischbacher, 2005; Van Lange et al., 2013), it must be noticed that the interpersonal orientations underlying social interactions have been studied mainly in terms of individual differences. The Social Values Orientation is a long-studied construct based on the relative 
weights people assign to their own and others' outcomes in situations of interdependence (Messick \& McClintock, 1968); people seeking to maximize their gains in a mixed-motive game are said to be Proself, whereas people concerned with other's gains and losses are said to be Prosocial. SVO has been identified as an important determinant of cooperative motives, strategies, and choice behaviour (Kollock, 1998; Balliet, Parks, \& Joireman, 2009). Nonetheless, there has been a growing consideration for an interactionist point of view (Kelley \& Thibalut, 1978), according to which interpersonal motives need to be taken into account; for instance, Van Lange and colleagues (Van Lange et al., 2007) proposed that interpersonal orientation cannot be studied separately from social interaction: "Interpersonal orientations are partially shaped by social interactions; therefore, shaped by the self, the interaction partner, and/or the situation" (ibidem, p. 551).Similarly, Boagaert and colleagues (Bogaert, Boone, \& Declerck, 2008), reviewing the literature on SVO and prosocial behaviour, conclude that the relationship between SVO and cooperative behaviour is mediated by the specific expectations concerning alters' behaviour. Once again, the empirical evidences of a generalised disposition to punish selfish behaviour and to reciprocate cooperative/altruistic behaviour (Gintis, 2000; Falk \& Fischbacher, 2006; Simpson \& WIller, 2008; Srang et al., 2016) call for an evolutionary basis of human prosocial behaviour. Moreover, according to a recent meta-analysis (Pletzer et al., 2018), Prosocials seem to expect more cooperation from others in social dilemmas, but even Proselfs are more likely to cooperate when they expect their partner to cooperate. Taken together, these indications support the hypothesis that different individual orientations to social values may benefit from a cooperative interpersonal context to foster prosocial behaviour.

\subsection{Moral Motives Underlying Prosocial Behaviour}

Even if the experimental game paradigm has brought a large body of evidence challenging the notion that human beings are merely self-interested actors (Yamagishi, 1995; Kollock, 1998; Fehr \& Gintis, 2007; Levitt \& List, 2007), a causal correspondence between the other-regarding behaviour and a specific motive cannot be easily assumed, since a same decision can be made according to different motives, values, and goals. Therefore, cooperative/altruistic behaviours, as can be measured through the outcomes of social games, should not be confounded with the "psychological" cooperative/altruistic motivations (West, Griffin \& Gardner, 2007; Clavien \& Klein, 2010). If we consider the SVO paradigm, in which motives are inferred by outcomes, proself behaviour may reflect an interpersonal orientation to individualism (enhancement of own outcomes), but also to competition (enhancement of relative advantage over others), and aggression (minimization of other's outcomes); similarly, prosocial behaviour may reflect an interpersonal orientation to cooperation (enhancement of joint outcomes) and equality (enhancement of equality in outcomes), but also to altruism (enhancement of other's outcomes) (Van Lange et al, 1997, 2007). Empirical 
evidence to support the direct influence of motives and values on behaviour has always been difficult to find (Hechter, Kim, \& Baer, 2005); in a recent study, Lin \& Wing-Tung (2014) showed that priming the PVQ values (Schwartz et al., 2001) influenced the resource allocation in the DG. A recent evolutionary perspective on human values can be found in the Moral Foundations Theory (MFT; Haidt \& Joseph, 2004, 2007; Haidt \& Graham, 2011; Graham et al., 2011; Graham et al., 2012). MFT claims that human morality originates from a finite number of innate mental systems shaped by both the evolution and by the environment; the five moral domains included in the first version of the theory by Haidt \& Joseph (2007) are: 1) Care, 2) Fairness, 3) Loyalty, 4) Authority, and 5) Sanctity. The MFT has been mainly applied to the field of individual and cultural differences (e.g. in politically liberal/conservative views), but we argue that it may as well suit the study of the moral motives underlying prosocial and proself choices. At present, we found a single study which used MFT in the DG (Feng et al. 2017); results show that a competition between Care and Fairness in individual traits could explain the disadvantageous effect of guilt on fair allocations: the Fairness foundation promoted equality in allocation, while the Care foundation promoted victim compensation.

\subsection{Distinguishing between Caregiving and Fairness in Prosocial Behaviour by Different Social Value Orientations}

Recently, building on a vast literature in motivational psychology, Bosworth, Singer, \& Snower (2016) claimed that changes in social settings may lead to changes in motives; they posited that different motives (wanting vs. caring) are activated in the interplay between individual dispositions and social settings (competitive vs. cooperative). Unfortunately, they did not distinguish between altruistic and cooperative motives. Another recent neurophysiological study by Hein et al. (2016), showed that: 1) distinct functional neural networks were involved in empathy-based and in reciprocity-based prosocial behaviour; 2) empathy-based altruism seemed to involve a more "basic" neural network than reciprocity; 3) the empathy induction only increased the frequency of other-regarding decisions in more selfish subjects, whereas the reciprocity induction only increased the frequency of other-regarding decisions in subjects with a prosocial orientation. In line with this study, our aim is to distinguish between caregiving-motivated and fairness-motivated behaviour in the DG. Our first hypothesis is that a fair-cooperative interpersonal context influences behaviour by imposing a fair share of the outcomes, where as a selfish-competitive interpersonal context allows a reduction of the share. Our second hypothesis is that Proselfs will tend to exploit a caregiving/altruistic interpersonal context, whilst Prosocials will not. Our third hypothesis is that a social mentality oriented to fairness and reciprocity will lead to a more equitable and stable pattern of sharing, and that individual differences in prosocial behaviour largely depend on people's willingness to stick to a cooperative/fair mentality in different interper- 
sonal situations.

\section{Method}

The present study is based upon a variant of the "dictator game" (DG) paradigm (Guala \& Mittone, 2010). DG is a decomposed game in which a player is to divide a sum of money between himself and another player; the player who decides the share is called the "dictator", since the other player has no influence on her decision; therefore, the amount of money given to the other is acknowledged as a measure of the player's "pure altruism" (Fehr \& Schmidt, 2005). To test our hypotheses, we introduced two payoff-irrelevant manipulations of the DG, which are supposed to influence the decisions because of a "framing effect" (Gerlach \& Jaeger, 2016). A first manipulation was introduced by depicting two different scenarios: one in which participants had to share a reward (i.e. a gain), and the other in which they should divide a cost (i.e. a loss). Since gains and losses are evaluated differently, the same amount being weighted more heavily when lost than when gained (Kahneman, Knetsch, \& Thaler, 1990; De Dreu, et al., 1994; Kühberger, 1998), the latter scenario should represent a more challenging condition for prosocial behaviour to emerge, and this should hold true for the Proself in particular (De Dreu \& Mc Cusker, 1997). A second manipulation was introduced by alternatively depicting the other as having selfish vs. fair vs. altruistic intentions towards the participants. We expect these different descriptions of the other (Levine, 1998) to modify the interpersonal context and, in turn, the resource allocation decisions.

\subsection{Participants}

We recruited online a total 125 volunteering participants (mean age: $27.3 ; \mathrm{F}=$ $63, \mathrm{M}=64)$. After having selected only those participants $(\mathrm{N}=111)$ who obtained a clear Social Values Orientation at the Triple-Dominance Measure of SVO scale (Van Lange et al., 1997), and having excluded participants ( $\mathrm{N}=14$ ) who failed to answer properly to the "catch" items of the 30-item Moral Foundations Questionnaire (MFQ, Graham, Haidt \& Nosek, 2008), analyses were conducted on a total sample of 96 participants (mean age: $27.2 ; \mathrm{F}=48, \mathrm{M}=48$ ), divided into two groups: Prosocial $(\mathrm{N}=65$; mean age: $27.2 ; \mathrm{F}=32, \mathrm{M}=33)$, and Proself $(\mathrm{N}=31$; mean age: $27.2 ; \mathrm{F}=16, \mathrm{M}=15)$. All statistical analyses were carried out with the IBM SPSS ${ }^{\odot}$ statistical package, v.19.

\subsection{Procedure}

The whole procedure was carried out online. After viewing a short debriefing video and completing the 9-Item Triple-Dominance Measure of SVO (Van Lange et al., 1997) and the MFQ scale (Graham, Haidt, \& Nosek, 2008; Bobbio, Nencini, \& Sarrica, 2011), participants were presented with two different scenarios. In the "Gain" scenario, they had to share a €30 reward (Figure 1), whereas 
in the "Loss" scenario they had to share a $€ 30$ cost (Figure 2).

For each of these two conditions, participants were presented with three different possible intentions of the other: 1) a "selfish" intention, in which the other was either willing to take all the reward for himself or to leave all the cost to the other; 2) a "fair" intention, in which the other was willing to equally divide both the reward and the cost; 3) an "altruistic" intention, in which the other was either willing to give all the reward to the other or to take all the cost for himself. It should be noticed that each of these intentions points to a different interpersonal motivational context: selfish intentions reveal a competitive motivational context, fair intentions reflect a cooperative motivational context, and altruistic intentions underlie a caregiving motivational context (Table 1).

To sum up, participants carried out six different resource allocation tasks, one for each of the three different intentions of the other ("selfish" vs. "fair" vs. "altruistic") in two different conditions (sharing a "gain" vs. sharing a "loss").

Finally, soon after each of the six resource allocation tasks, participants had to rate, on a five-point scale, how much their decision had been a matter of: 1) altruism and empathy; 2) fairness and reciprocity; 3) loyalty and team play; 4) respect of the rules; 5) pride and dignity. These five visual-analogue scales (VAS) were meant to correspond to the five main moral domains as described in the Moral Foundations Theory (MFT; Haidt \& Joseph, 2004, 2007; Haidt \& Graham, 2011). Moreover, in terms of the evolutionary motivational systems theory, altruism and empathy are key features of the social mentality that characterizes the caregiving system, whereas fairness and reciprocity are key features of the social mentality that defines the cooperative system (Liotti \& Gilbert, 2011).

Although there are no clear-cut indications on the effect of paying subjects in the DG (Forsythe et al., 1994; Balliet, Parks, \& Joireman, 2009), in order to make the resource allocation task more realistic, participants were informed that $10 \%$ of them would have been randomly selected and paid according to their share; if, for instance, a participant had decided to give $€ 10$ to the selfish other in the "gain" scenario, and if this decision would had been randomly selected, the participant would have received $€ 20$ as a reward (i.e. the $€ 30$ total amount minus the money she would have given to the other).

"You are in a mall, and someone has lost the car keys inside it. An announcement warns that anyone who will find them can withdraw a reward of $€ 30$ by delivering them to the reception. While you and another customer are taking the parking elevator, you both find the keys, hidden behind the sliding door of the elevator. So, you've won the $€ 30$ reward"

Figure 1. The "Gain” scenario.

"You are in a gift shop. As you walk through the shelves, some fragile objects fall apart from an exhibitor next to you, and something breaks. Meanwhile, another customer besides you was passing by; therefore, you both do not know who caused the damage. By checking, you find out that an item worth $€ 30$ was broken. A sign warns that broken goods will have to be refunded. So, you now will have to refund the damage of $€ 30$ "

Figure 2. The "Loss" scenario. 
Table 1. Intentions of the Other inthe two scenarios ("Gain" vs. "Loss").

\begin{tabular}{clll}
\hline \multirow{2}{*}{$\begin{array}{c}\text { Intentions of the } \\
\text { Other (IO) }\end{array}$} & $\begin{array}{c}\text { Interpersonal } \\
\text { context }\end{array}$ & \multicolumn{1}{c}{ Scenario (SC) } \\
\cline { 3 - 4 } Selfish & Competition & $\begin{array}{l}\text { He wants to take the credits } \\
\text { and the reward for himself. }\end{array}$ & $\begin{array}{l}\text { He wants you to take the } \\
\text { blame and the costs. } \\
\text { Fair }\end{array}$ \\
Cooperation & $\begin{array}{l}\text { He wants to share the } \\
\text { credits and the reward. }\end{array}$ & $\begin{array}{l}\text { He wants to share the } \\
\text { responsibility and the costs }\end{array}$ \\
Altruistic & Caregiving & $\begin{array}{l}\text { He wants to give you the } \\
\text { credits and the reward. }\end{array}$ & $\begin{array}{l}\text { He wants to take the } \\
\text { responsability and pay all } \\
\text { the costs. }\end{array}$ \\
\hline
\end{tabular}

\section{Results}

\subsection{Prosocial Behaviour}

All data on the resource allocation task (i.e. the amount of money given to the other) were analysed in a $2 \times 2 \times 3$ MANOVA mixed model, with the Social Values Orientation (SVO $=$ Prosocial vs. Proself) as a between-subjects variable, and the Scenario (SC = gain vs. loss) and the Intention of the Other ( $\mathrm{IO}=$ selfish vs. fair vs altruistic) as within-subjects variables. Results are shown in Table 2 (mean values) and in Table 3 (MANOVA).

All main effects and interactions reached statistical significance. The overall pattern of results is specified by a third-order interaction $\mathrm{SVO} \times \mathrm{SC} \times \mathrm{IO}\left(\mathrm{F}_{(2,188)}\right.$ $=6.53, p=.002$ ), that can be read for the two sub-groups separately (Figure $3 \&$ Figure 4). Prosocial participants penalized selfish intentions, in both conditions, by giving about $30 \%$ of the total amount, whereas they steadily gave about a half of the total amount in all the remaining conditions. Proself participants also penalized the selfish other in both conditions by giving between 25\% (in the "gain" condition) and 20\% (in the "loss" condition) of the total amount. Furthermore, they shared a half of the money with the fair other in both conditions, and with the altruistic other when dealing with a gain. However, when sharing a loss, they dramatically reduced the amount of resources allocated to the altruistic other by giving, on average, less than $30 \%$ of their money. In other words, when facing with a loss, Proselfs seemed to take advantage of the altruistic intentions of the other instead of reciprocating them.

The one-way ANOVAs confirmed that the only significant differences emerged: 1) between Prosocials and Proselfs, in the "Loss" condition, when the other had selfish intentions $\left.\left(\mathrm{F}_{(1.94)}=4.33 ; p .=.040\right) ; 2\right)$ in the same condition, when the other had altruistic intentions $\left.\left(\mathrm{F}_{(1.94)}=14.62 ; p .=.000\right) ; 3\right)$ within Proself participants, when the other had altruistic intentions, between the "Gain" and the "Loss" condition $\left(\mathrm{F}_{(1.30)}=18.45 ; p .=.000\right)$.

\subsection{Relevant Interpersonal Motives}

\section{1) Moral Foundations Questionnaire:}

The MANOVA showed a significant difference in the MFQ between Prosocials and Proselfs at a multivariate level (Roy's $\mathrm{R}=.139, \mathrm{~F}=2.51, p .=.036$ ). A 
Table 2. Resource Allocation Task-Mean Values.

\begin{tabular}{cccccc}
\hline & & \multicolumn{3}{c}{ Social Values Orientation (SVO) } \\
\cline { 3 - 6 } & \multicolumn{2}{c}{ Prosocial } & \multicolumn{2}{c}{ Proself } \\
\hline \multirow{2}{*}{ Scenario (SC) } & Intention of the Other (IO) & Mean & $S d$ & mean & sd \\
\hline \multirow{2}{*}{ Gain } & Selfish other & 11.15 & 10.41 & 8.06 & 9.72 \\
& Fair other & 15.23 & 4.19 & 15.48 & 2.99 \\
& Altruistic other & 15.08 & 4.46 & 16.29 & 6.19 \\
\cline { 3 - 6 } Loss & Selfish other & 10.69 & 9.51 & 6.45 & 8.96 \\
& Fair other & 15.00 & 3.31 & 14.84 & 0.90 \\
& Altruistic other & 14.92 & 6.46 & 9.19 & 7.65 \\
\hline
\end{tabular}

Table 3. Resource Allocation Task-MANOVA.

\begin{tabular}{cccccc}
\hline \multirow{2}{*}{ Source } & \multicolumn{5}{c}{ MANOVA $2 \times 2 \times 3$} \\
\cline { 2 - 6 } & SS & Df & MS & F & p. \\
\hline SVO $^{\mathrm{a}}$ & 483.33 & 1 & 483.33 & 4.917 & 0.029 \\
Error (SVO) & 9240.23 & 94 & 98.30 & - & - \\
SC $^{\mathrm{b}}$ & 364.03 & 1 & 364.03 & 7.758 & 0.006 \\
SVOxSC $_{\text {Error (SC) }}$ & 253.27 & 1 & 253.27 & 5.397 & 0.022 \\
IO & 4410.93 & 94 & 46.92 & - & - \\
SVO $\times$ IO & 3416.20 & 2 & 1708.10 & 34.068 & 0.000 \\
error (IO) & 294.68 & 2 & 147.34 & 2.939 & 0.055 \\
SC $\times$ IO & 9425.90 & 188 & 50.14 & - & - \\
SVO $\times$ SC $\times$ IO & 240.91 & 2 & 120.46 & 5.860 & 0.003 \\
Error (SC $\times$ IO) & 268.34 & 2 & 134.17 & 6.527 & 0.002 \\
\hline
\end{tabular}

a. $\mathrm{SVO}=$ Social Values Orientation; $\mathrm{b} . \mathrm{SC}=\mathrm{Scenario}$; . IO = Intention of the Other.

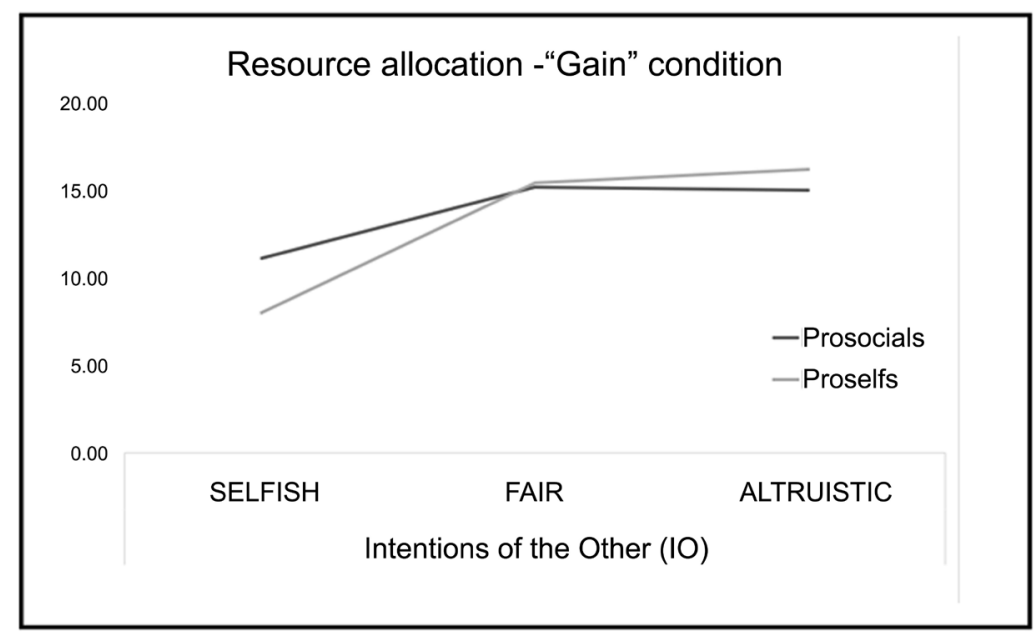

Figure 3. Prosocial behaviour when sharing a reward ("Gain” condition). 


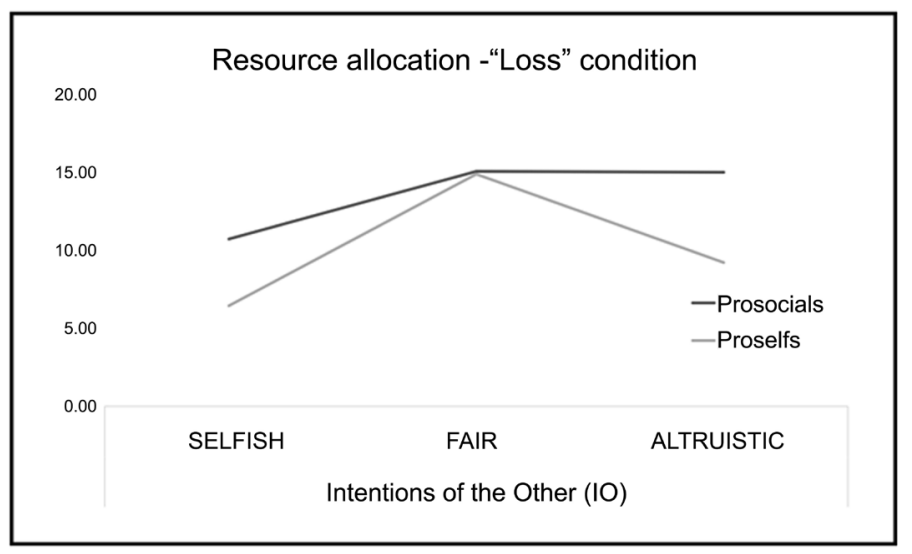

Figure 4. Prosocial behaviour when sharing a cost ("Loss" condition).

series of one-way ANOVAs between groups showed that, at the univariate level, the Prosocial participants obtained significantly higher scores in the Care $\left(\mathrm{F}_{(1.94)}\right.$ $=2.95 ; p .=.015)$ and in the Fairness $\left(\mathrm{F}_{(1.94)}=8.74 ; p .=.004\right)$ moral domains of the MFQ. Differences in the remaining moral domains did not reach statistical significance (mean values of the MFQ are shown in Table 4):

In order to assess which moral domains better accounted for the decisions in the DG tasks, a series of linear multiple regressions (stepwise method) was carried out. In a first regression model, the overall amount of money given in the six resource allocation tasks was inserted as dependent variable, and the five MFQ scores were inserted as predictors; the scores in the Fairness domain resulted to predict the overall resource allocation in the DG $(\beta=.44 ; \mathrm{t}=4.74 ; p$. $=.000)$. A further mediation analysis ${ }^{1}$ was carried out with the overall amount of shared money in the six resource allocation as dependent variable $(\mathrm{Y})$, the SVO as independent variable $(\mathrm{X})$, and the five scores of the MFQ as mediators (M); Fairness alone mediated the relation between SVO and the amount of shared money (effect $=.74, \mathrm{SE}=.43,95 \% \mathrm{CI}[.10,1.75])$. Thus, individual differences in the moral domain of Fairness (and not in Care) resulted to account for the impact of the SVO on the overall share in the DG.

\section{2) Visual Analogue Scales (VAS) of the relevant motives:}

To assess the specific role of interpersonal motives in the DG decisions, a further series of regression models was carried out for the six different allocation tasks separately and using the scores at the five VAS of relevant motives as predictors: Altruism and Empathy (AE), Fairness and Reciprocity (FR), Loyalty and Team Play (LT) Respect of the Rules (RR), Pride and Dignity (PD). Again, mediation analyses were used to see which interpersonal motives explained the differences between Prosocials and Proselfs. To begin with the "Gain" condition, when the other showed altruistic intentions, the amount of shared money in the DG was predicted by AE $(\beta=.22 ; \mathrm{t}=2.20 ; p .=.03)$. However, none of the VAS mediated the relation between SVO and allocated resources. No other regression

${ }^{1}$ Mediation analyses were carried out with the PROCESS $^{\oplus}$ macro for SPSS ${ }^{\odot}$, v.3 (Hayes, 2018; http://www.processmacro.org/download.html). 
Table 4. Moral Foundations Questionnaire (MFQ)—Mean Values.

\begin{tabular}{ccccc}
\hline & \multicolumn{4}{c}{ Social Values Orientation (SVO) } \\
\cline { 2 - 5 } & \multicolumn{2}{c}{ Prosocial } & \multicolumn{3}{c}{ Proself } \\
\hline Moral Foundations & mean & $s d$ & Mean & $s d$ \\
\hline Care & 3.77 & 0.67 & 3.39 & 0.74 \\
Fairness & 3.93 & 0.63 & 3.51 & 0.71 \\
Loyalty & 2.77 & 0.78 & 2.96 & 0.53 \\
Authority & 2.14 & 0.79 & 2.38 & 0.75 \\
Sanctity & 1.84 & 0.82 & 1.96 & 0.84 \\
\hline
\end{tabular}

and mediation models were significant in the "Gain" condition. In the "Loss" condition, when the other showed fair intentions, FR predicted the resource allocation $(\beta=.37 ; \mathrm{t}=3.87 ; p .=.000)$, but no mediation effects emerged. Finally, when the other showed altruistic intentions, giving more was found to be a matter of Fairness/Reciprocity $(\beta=.60 ; \mathrm{t}=7.23 ; p .=.000)$; moreover, FR mediated the effect of SVO on the DG (effect $=2.68, \mathrm{SE}=.98,95 \%$ CI $[.93,4.72])$.

\section{Discussion}

As already stated, converging evidences from different fields of study support the evolutionary claim that other-regarding tendencies are part of the human nature; yet, it would be useful to deepen our knowledge of how and why self-interest prevails in some cases. Here we hypothesized that individual differences in general SVO express themselves according to the interpersonal motivational context, and that a cooperative social mentality leads to a more stable prosocial behaviour. Taken together, our results are in line with this hypothesis. As a first result, when the interpersonal context was framed in a selfish/competitive way, the amount of shared money in the DG tended to decrease, with the SVO accounting for minimal differences. The absence of a clear relation between this strong and notorious effect and any of the considered interpersonal motives suggests that there may be more than one subjective explanation for this: someone may feel free to act selfishly, whilst someone else may intend to punish selfish-minded people, but reciprocity may also be the underlying principle, and so forth. A second result was that when the interpersonal context was framed in a fair/cooperative way, an equitable share emerged irrespective of SVO. Interestingly, a fair share of gains was not found to be uniquely driven by fairness, whereas sharing a loss with equity clearly was a matter of fairness. A third and most intriguing pattern of results emerged when the interpersonal context was framed in an altruistic/caregiving way: in the gain condition, an equitable sharing was fostered by altruistic motives when the other had altruistic intentions; more interestingly, when the DG was framed in terms of loss, only Prosocials stuck to an equitable sharing behaviour, and this was be- 
cause of their willingness to make it a matter of fairness and reciprocity and keep a co-operative social mentality. On the contrary, loosing this mentality seemingly caused Proselfs to reduce their share, and the absence of a clear interpersonal motive for their behaviour suggests that they may either adopt a caregiving/care-seeking interpersonal framework by assuming the role of the needy one in the relation (i.e. accepting the other's care), or may they adopt a more competitive interpersonal framework by exploiting the other's generosity. Both explanations make sense by an evolutionary point of view; in the first case, being altruistic to someone in need may initiate an interpersonal exchange of caregiving/caretaking; in the second case, the other's willingness to sustain a cost may be read as a submissive behaviour which initiates a dominant behaviour, e.g. keeping a limited resource for themselves. Either way, we may conclude that framing the interpersonal context in terms of caregiving was less conducive to an equitable share than framing it in terms of peer cooperation, because this latter framing was the one which best fostered a fair and cooperative social mentality in all participants. We find that our conclusions are in line with the notion that the principle of equality is the more solid basis of any just behaviour (Messick, 1993); they are also coherent with the original distinction made by J.S. Mill between justice and charity: "justice implies something which is not only right to do, and wrong not to do, but which some individual can claim from us as his moral right. No one has a moral right to our generosity or beneficence, because we are not morally bound to practice those virtues towards any given individual. This feature (...) constitutes the specific difference between justice and generosity or beneficence" (Mill, 1871 in Ryan, 1993: p. 59). This study has several limitations; amongst them, the use of only two scenarios for the gain/loss framing, and the subjective measurement of motivations which may not correspond to the actual motivation, either because participants may give post-hoc explanations for their behaviour, and because they may tend to give the answer they consider more appropriate. In future studies, more than one scenario for the gain/loss condition can be adopted, and a caregiving motivation can be prompted more directly by depicting the other as in condition of necessity. Nevertheless, the possibility that the interpersonal context can foster prosocial behaviour by promoting a cooperative social mentality in people with different personal orientations towards social values and morality, is potentially relevant for many applicative purposes, in the educational, the organizational, and the clinical psychology field. Relationally-oriented clinical psychologists have already put forward the hypothesis that peer cooperation is a more effective agent of therapeutic change than empathic concern (Safran \& Muran, 2000; Stern, 2004; King-Casas et al, 2008; Colli \& Lingiardi, 2009; Liotti \& Gilbert, 2011, Cortina \& Liotti, 2014). Future research could also be aimed at better understanding the developmental relation between the caregiving and peer-cooperation mechanisms; since care precedes fairness in the evolution of moral systems (Tomasello, 2016), it could be interesting to understand to what extent caregiving may favour the 
development of peer cooperation and under what circumstances it may eventually hamper it instead.

\section{Acknowledgements}

We wish to dedicate this research to the memory of dr. Giovanni Liotti (1945-2018), who gifted us all with his inspiring theories and inextinguishable scientific curiosity.

\section{References}

Balliet, D., Parks, C., \& Joireman, J. (2009). Social Value Orientation and Cooperation in Social Dilemmas: a Meta-Analysis. Group Processes \& Intergroup Relations, 12, 533-547. https://doi.org/10.1177/1368430209105040

Bernard, L., Mills, M., Swenson, L., \& Walsh, R. P. (2005). An Evolutionary Theory of Human Motivation. Genetic, Social, and General Psychology Monographs, 131, 129-184. https://doi.org/10.3200/MONO.131.2.129-184

Bobbio, A., Nencini, A., \& Sarrica, M. (2011). Il Moral Foundation Questionnaire: Analisi della struttura fattoriale della versione italiana. Giornale di Psicologia, 5, 7-18.

Bogaert, S., Boone, C., \& Declerck, C. (2008), Social Value Orientation and Cooperation in Social Dilemmas: A Review and Conceptual Model. British Journal of Social Psychology, 47, 453-480. https://doi.org/10.1348/014466607X244970

Bosworth, S. J., Singer, T., \& Snower, D. J. (2016). Cooperation, Motivation and Social Balance. Journal of Economic Behaviour\& Organization, 126-B, 72-94. https://doi.org/10.1016/j.jebo.2015.12.005

Bowlby, J. (1969). Attachment and Loss-Volume I: Attachment. In Basic Books (2nd ed.). New York City: Basic Books NYC.

Bowlby, J. (1982). Caring for Children: Some Influences on Its Development. In R. S. Cohen, S. H. Weissman, \& B. J. Cohler (Eds.), Parenthood. New York: The Guilford Press.

Clavien, C., \& Klein, R. A. (2010). Eager for Fairness or for Revenge? Psychological Altruism in Economics. Economics and Philosophy, 26, 267-290. https://doi.org/10.1017/S0266267110000374

Colli, A., \& Lingiardi, V. (2009). The Collaborative Interactions Scale: A New Transcript-Based Method for the assessment of Therapeutic Alliance Ruptures and Resolutions in Psychotherapy. Psychotherapy Research, 19, 718-734. https://doi.org/10.1080/10503300903121098

Cortina, M., \& Liotti, G. (2005). Toward a Multimotivational and Intersubjective Model of Human Nature. Paper Presented on June 11, 2005, at the Annual Meeting of the Rapaport-Klein Study Group. http://www.psychomedia.it/rapaport-klein/cortina+liotti05.htm

Cortina, M., \& Liotti, G. (2010). The Intersubjective and Cooperative Origins of Consciousness: An Evolutionary-Developmental Approach. Journal of the American Academy of Psychoanalysis and Dynamic Psychiatry, 38, 291-314. https://doi.org/10.1521/jaap.2010.38.2.291

Cortina, M., \& Liotti, G. (2014). An Evolutionary Outlook on Motivation: Implications for the Clinical Dialogue. Psychoanalytic Inquiry: A Topical Journal for Mental Health Professionals, 34, 864-899. https://doi.org/10.1080/07351690.2014.968060

Darwin, C. (1874). The Descent of Man (2nd ed.). Princeton, NJ: Princeton University 
Press, 1981.

De Dreu, C. K. W., \& McCusker, C. (1997). Gain-Loss Frames and Cooperation in Two-Person Social Dilemmas: A Transformational Analysis. Journal of Personality and Social Psychology, 72, 1093-1106. https://doi.org/10.1037/0022-3514.72.5.1093

De Dreu, C. K. W., Emans, B. J. M., Van de Vliert, E., \& Carnevale, P. J. (1994). Effects of Gain-Loss Frames in Negotiation: Loss Aversion, Mismatching, and Frame Adoption. Organizational Behavior and Human Decision Processes, 60, 90-107. https://doi.org/10.1006/obhd.1994.1076

De Waal, F. B. M. (2006). Primates and Philosophers: How Morality Evolved. Princeton, NJ: Princeton University Press. https://doi.org/10.1515/9781400830336

De Waal, F. B. M., Churchland, P. S., Pievani, T., \& Parmigiani, S. (2014). Evolved Morality: The Biology and Philosophy of Human Conscience. Leiden-Boston: Brill.

Dunbar, R. I. (1998). The Social Brain Hypothesis. Evolutionary Anthropology, 6, 178-190.

https://doi.org/10.1002/(SICI)1520-6505(1998)6:5<178::AID-EVAN5>3.0.CO;2-8

Falk, A., \& Fischbacher, U. (2006). A Theory of Reciprocity. Games and Economic Behaviour, 54, 293-315. https://doi.org/10.1016/j.geb.2005.03.001

Fehr, E., \& Fischbacher, U. (2005). Human Altruism-Proximate Patterns and Evolutionary Origins. Analyse \& Kritik, 27, 6-47. https://doi.org/10.1515/auk-2005-0101

Fehr, E., \& Gintis, H. (2007). Human Motivation and Social Cooperation: Experimental and Analytical Foundations. Annual Review of Sociology, 33, 43-64. https://doi.org/10.1146/annurev.soc.33.040406.131812

Fehr, E., \& Schmidt, K. M. (2005). The Economics of Fairness, Reciprocity and Altruism-Experimental Evidence and New Theories. Munich Discussion Paper, No. 2005-20.

Feng, Q., Xu, Y., Xu, R., \& Zhang, E. (2017). Moral Foundations Tell Us Why Guilt Induces Unfair Allocation in Multi-Party Interactions. Asian Journal of Social Psychology, 20, 191-200. https://doi.org/10.1111/ajsp.12170

Forsythe, R., Horowitz, J. L., Savin N. E., \& Sefton M. (1994). Fairness in Simple Bargaining Experiments. Games and Economic Behaviour, 6, 347-369. https://doi.org/10.1006/game.1994.1021

Fox, K. C. R., Muthukrishna, M., \& Shultz, S. (2017). The Social and Cultural Roots of Whale and Dolphin Brains. Nature, Ecology and Evolution, 1, 1699-1705.

George, C., \& Solomon, J. (2008). The Caregiving System: A Behavioural Systems Approach to Parenting. In J. Cassidy, \& P. R. Shaver (Eds.), Handbook of Attachment: Theory, Research and Clinical Applications (2nd ed., pp. 833-856). New York, NY: Guilford Press.

Gerlach, P., \& Jaeger, B. (2016). Another Frame, Another Game? In A. Hopfenspitz, \& E. Lori (Eds.), Proceedings of Norms, Actions, Games. Toulouse: Institute for Advanced Studies.

Gilbert, P. (1989). Human Nature and Suffering. London: Erlbaum.

Gintis, H. (2000). Strong Reciprocity and Human Sociality. Journal of Theoretical Biolo$g y, 206,169-179$. https://doi.org/10.1006/jtbi.2000.2111

Graham, J., Haidt, J., \& Nosek, B. A. (2008). The Moral Foundations Questionnaire.

Graham, J., Haidt, J., Koleva, S., Motyl, M., Iyer, R., Wojcik, S. P., \& Ditto, P. H. (2012). Moral Foundations Theory: The Pragmatic Validity of Moral Pluralism. Advances in 
Experimental Social Psychology, Forthcoming, 47, 55-130.

https://ssrn.com/abstract=2184440

Graham, J., Nosek, B. A., Haidt, J., Iyer, R., Koleva, S., \& Ditto, P. H. (2011). Mapping the Moral Domain. Journal of Personality and Social Psychology, 101, 366-385. https://doi.org/10.1037/a0021847

Guala, F., \& Mittone, L. (2010). Paradigmatic Experiments: The Dictator Game. The Journal of Socio-Economics, 39, 578-584. https://doi.org/10.1016/j.socec.2009.05.007

Haidt, J., \& Graham, J. (2011). Mapping Moral Domain. Journal of Personality and Social Psychology, 101, 366-385. https://doi.org/10.1037/a0021847

Haidt, J., \& Joseph, C. (2004). Intuitive Ethics: How Innately Prepared Intuitions Generate Culturally Variable Virtues. Daedalus, 133, 55-66. https://doi.org/10.1162/0011526042365555

Haidt, J., \& Joseph, C. (2007). The Moral Mind: How 5 Sets of Innate Moral Intuitions Guide the Development of Many Culture-Specific Virtues, and Perhaps Even Modules. In P. Carruthers, S. Laurence, \& S. Stich (Eds.), The Innate Mind, Vol. 3. Foundations and the Future. Oxford: Oxford University Press.

Hechter, M., Kim, H., \& Baer, J. (2005). Prediction versus Explanation in the Measurement of Values. European Sociological Review, 21, 91-108. https://doi.org/10.1093/esr/jci006

Hein, G., Morishima, Y., Leiberg, S., Sul, S., \& Fehr, E. (2016). The Brain's Functional Network Architecture Reveals Human Motives. Science, 351, 1074-1078. https://doi.org/10.1126/science.aac7992

Jenesen, K. (2016). Prosociality. Current Biology, 26, R748-R752. https://doi.org/10.1016/j.cub.2016.07.025

Kahneman, D., Knetsch, J. L., \& Thaler, R. H. (1986). Fairness and the Assumption of Economics. The Journal of Business, 59, S285-S300.

Kahneman, D., Knetsch, J. L., \& Thaler, R. H. (1990). Experimental Tests of the Endowment Effect and the Coase Theorem. Journal of Political Economy, 98, 1325-1348.

https://doi.org/10.1086/261737

Kelley, H. H., \& Thibaut, J. W. (1978). Interpersonal Relations: A Theory of Interdependence. New York, NY: Wiley.

King-Casas, B., Sharp, C., Lomax-Bream, L., Lohrenz, T., Fonagy, P., \& Read Montague, P. (2008). The Rupture and Repair of Cooperation in Borderline Personality Disorders. Science, 321, 806-810. https://doi.org/10.1126/science.1156902

Kollock, P. (1998). Social Dilemmas: The Anatomy of Cooperation. Annual Review of Sociology, 24, 183-214. https://doi.org/10.1146/annurev.soc.24.1.183

Kühberger, A. (1998). The Influence of Framing on Risky Decisions: A Meta-Analysis. Organizational Behavior and Human Decision Processes, 75, 23-55. https://doi.org/10.1006/obhd.1998.2781

Levine, D. (1998). Modeling Altruism and Spitefulness in Experiments. Review of Economic Dynamics, 1, 593-622. https://doi.org/10.1006/redy.1998.0023

Levitt, S. D., \& List, J. A. (2007). What Do Laboratory Experiments Measuring Social Preferences Reveal about the Real World? Journal of Economic Perspectives, 21, 153-174. https://doi.org/10.1257/jep.21.2.153

Lichtenberg, J. D. (1989). Psychoanalisys and Motivation. Hillsdale, NJ: Analytic Press.

Lin, T., \& Wing-Tung, A. (2014). Values, Self and Other-Regarding Behaviour in the 
Dictator Game. Rationality and Society, 26, 46-72.

Liotti, G. (1989). Attachment and Cognition. In C. Perris, I. Blackburn, \& H. Perris (Eds.), The Theory and Practice of Cognitive Psychotherapy (pp. 71-99). New York, NY: Springer.

Liotti, G. (2001). Le opere della coscienza. Psicopatologia e psicoterapia nella prospettiva Cognitivo-Evoluzionista. Milano: Raffaello Cortina.

Liotti, G., \& Gilbert, P. (2011). Mentalizing, Motivation, and Social Mentalities: Theoretical Considerations and Implications for Psychotherapy. Psychology and Psychotherapy: Theory, Research and Practice, 84, 9-25.

Liotti, G., Fassone, G., \& Monticelli, F. (2017). L'evoluzione delle emozioni e dei sistemi motivazionali. Milano: Raffaello Cortina.

Messick, D. M. (1993). Equality as a Decision Heuristic. In B. A. Mellers, \& J. Baron (Eds.), Psychological Perspectives on Justice: Theory and Applications (pp. 11-31). Cambridge, MA: Cambridge University Press. https://doi.org/10.1017/CBO9780511552069.003

Messick, D. M., \& McClintock, C. G. (1968). Motivational Basis for Choice in Experimental Games. Journal of Experimental Social Psychology, 4, 1-25. https://doi.org/10.1016/0022-1031(68)90046-2

Mikulincer, M., Shaver, P. R., Gillath, O., \& Nitzberg, R. A. (2005). Attachment, Caregiving, and Altruism: Boosting Attachment Security Increases Compassion and Helping. Journal of Personality and Social Psychology, 89, 817-839. https://doi.org/10.1037/0022-3514.89.5.817

Mill, J. S. (1836). On the Definition of Political Economy, and on the Method of Investigation Proper to It. London and Westminster Review, October 1836. In Essays on Some Unsettled Questions of Political Economy (2nd ed.). London: Longmans, Green, Reader \& Dyer.

Mill, J. S. (1871). On the Connection between Justice and Utility. In A. Ryan (Ed.), Justice (pp. 51-72). Oxford: Oxford University Press.

Ogden, P., Minton, K. \& Pain, C. (2006). Trauma and the Body: A Sensorimotor Approach to Psychotherapy (Norton Series on Interpersonal Neurobiology). New York City: Basic Books NYC.

Panksepp, J. (1998). Affective Neuroscience: The Foundations of Human and Animal Emotions. Oxford: Oxford University Press.

Pérez-Barbería, F. J., Shultz, S., \& Dunbar, R. I. (2007). Evidence for Coevolution of Sociality and Relative Brain Size in Three Orders of Mammals. Evolution, 61, 2811-2821. https://doi.org/10.1111/j.1558-5646.2007.00229.x

Pletzer, J. L., Balliet, D., Joireman, J., Kuhlman, M., Voelpel, S. C., \& Van Lange, P. A. M. (2018). Social Value Orientation, Expectations, and Cooperation in Social Dilemmas: A Meta-Analysis. European Journal of Personality, 32, 62-83. https://doi.org/10.1002/per.2139

Safran, J. D. \& Muran, J. C. (2000). Negotiating the Therapeutic Alliance: A Relational Treatment Guide. New York, NY: Guilford.

Schmidt, M. F. H., \& Sommerville, J. A. (2011). Fairness Expectations and Altruistic Sharing in 15-Month-Old Human Infants. PLOS ONE, 6, e23223. https://doi.org/10.1371/journal.pone.0023223

Schwartz, S. H., Melech, G., \& Lehmann, A. (2001). Extending the Cross-Cultural Validity of the Theory of Basic Human Values with a Different Method of Measurement. 
Journal of Cross-Cultural Psychology, 32, 519-542.

https://doi.org/10.1177/0022022101032005001

Simpson, B., \& Willer, R. (2008). Altruism and Indirect Reciprocity: The Interaction of Person and Situation in Prosocial Behavior. Social Psychology Quarterly, 71, 37-52. https://doi.org/10.1177/019027250807100106

Solomon, J., \& George, C. (1996). Defining the Caregiving System: Toward a Theory of Caregiving. Infant Mental Health Journal, 17, 183-197. https://doi.org/10.1002/(SICI)1097-0355(199623)17:3<183::AID-IMHJ1>3.0.CO;2-Q

Sommerville, J. A., Schmidt, M. F. H., Yun, J., \& Burns, M. (2012). The Development of Fairness Expectations and Prosocial Behaviour in the Second Year of Life. Infancy, 18, 40-66. https://doi.org/10.1111/j.1532-7078.2012.00129.x

Srang, S., Grote, X., Kuss, K., Park, S. Q., \& Weber, B. (2016). Generalized Negative Reciprocity in the Dictator Game-How to Interrupt the Chain of Unfairness. Scientific Reports, 6, Article No. 22316. https://doi.org/10.1038/srep22316

Stern, D. (2004). The Present Moment in Psychotherapy and Everyday Life (Norton Series on Interpersonal Neurobiology). New York City: Basic Books NYC.

Street, S. E., Navarrete, A. F., Reader, S. M., \& Laland, K. N. (2017). Coevolution of Cultural Intelligence, Extended Life History, Sociality, and Brain Size in Primates. Proceedings of the National Academy of Sciences of the United States of America, 114, 7908-7914. https://doi.org/10.1073/pnas.1620734114

Swain, J.-E., Konrath, S., Brown, S. L., Finegood, E. D., Akce, L. B, Dayton, C. J., \& Shaun, S. H. (2012). Parenting and Beyond: Common Neurocircuits Underlying Parental and Altruistic Caregiving. Parenting: Science and Practice, 12, 115-123. https://doi.org/10.1080/15295192.2012.680409

Thibault, J. W., \& Kelley, H. H. (1959). The Social Psycholology of Groups. New York, NY: John Wiley \& Sons.

Tomasello, M. (1999) The Cultural Origins of Human Cognition. Cambridge, MA: Harvard University Press.

Tomasello, M. (2009). Why We Cooperate (Boston Review Books). New York City: Basic Books NYC.

Tomasello, M. (2016). A Natural History of Human Morality. Cambridge, MA: Harvard University Press. https://doi.org/10.4159/9780674915855

Van der Hart, O., Nijenhuis, E. R. S., \& Steele, K. (2006). The Haunted Self: Structural Dissociation and the Treatment of Chronic Traumatization. New York/London: WW Norton \& Co.

Van Lange, P. A. M., De Cremer, D., Van Dijk, E., \& Van Vugt, M. (2007). Self-Interest and Beyond. Basic Principles of Social Interaction. In A. W. Kruglanski, \& E. T. Higgings (Eds.), Social Psychology: Handbook of Basic Principles (pp. 540-561). New York, NY: Guilford.

Van Lange, P. A. M., Joireman, J., Parks, C. D., \& Van Dijk, E. (2013). The Psychology of Social Dilemmas: A Review. Organizational Behavior and Human Decision Processes, 120, 125-141. https://doi.org/10.1016/j.obhdp.2012.11.003

Van Lange, P. A. M., Otten, W., De Bruin, E., \& Joireman, J. A. (1997). Development of Prosocial, Individualistic, and Competitive Orientations: Theory and Preliminary Evidence. Journal of Personality and Social Psychology, 73, 733-746.

https://doi.org/10.1037/0022-3514.73.4.733

Von Neumann, J., \& Morgenstern, O. (1944). Theory of Games and Economic Behaviour. 
Princeton, NJ: Princeton University Press.

West, S. A., Griffin, A. S., \& Gardner, A. (2007). Social Semantics: Altruism, Cooperation, Mutualism, Strong Reciprocity and Group Selection. Journal of Evolutionary Biology, 20, 415-432. https://doi.org/10.1111/j.1420-9101.2006.01258.x

Yamagishi, T. (1995). Social Dilemmas. In: K. S. Cook, G. A. Fine, \& H. James (Eds.), Sociological Perspectives on Social Psychology (pp. 311-335). Needham Heights, MA: Allyn \& Bacon. 